Volume 1, Number 2, 2015

\title{
Gas Dynamical Capillary Flowmeters of Small and Micro Flowrates of Gases
}

\author{
Ivan Stasiuk ${ }^{*}$ \\ Lviv Polytechnic National University, 12 S. Bandera St., Lviv, 79013, Ukraine
}

Received: November 20, 2015. Revised: December 08, 2015. Accepted: December 15, 2015.

(C) 2015 The Authors. Published by Lviv Polytechnic National University.

\begin{abstract}
The possibility of application of glass capillary tubes (CTs) as sensors of small and micro flowrates of gases was justified. The accuracy of a number of CTs flowrate equations was analyzed on the basis of experimental studies of CTs flowrate characteristics. It was shown that CTs can be applied as primary devices of small and micro flowrates of gases without individual calibration. The results of studies on the dynamic properties of gas dynamical capillary flowmeters of small and micro flowrates of gases constructed on the basis of glass CTs in the branches of a measuring bridge diagram are presented. The effects of various factors on the dynamic properties of the gas dynamical capillary flowrate transducers (GDCFTs) were analyzed. Recommendations on construction of the inter-capillary pneumatic measuring chambers (PMCs) of GDCFTs to provide the needed dynamic properties of the flowmeters are presented. The technique for defining the needed ratio of PMCs volumes in a GDCFT to provide the needed dynamic properties of the flowmeters on the stage of their design and construction is described.
\end{abstract}

Keywords: capillary tube; small and micro flowrates of gas; accuracy; time constant.

\section{Objectives and problems in measurement of small and micro flowrates of gases}

Small and micro flowrates of gases need to be measured when monitoring small gas flows. Such flows are present in new technologies of up-to-date industrial manufacturing of fiber optic cables, semiconductor devices, integrated circuits and other devices of microelectronics. There is also a need to measure small and micro flowrates of gases during metrological certification of gas analytical measuring equipment and during research works. Micro flowrates of gases are the flowrates from 0 to $3 \cdot 0 \cdot 10^{-6} \mathrm{~m}^{3} / \mathrm{s}$ in pipes with the internal diameter of 1 to $5 \mathrm{~mm}$. Small flowrates are the flowrates from $3.0 \cdot 10^{-6}$ to $3.0 \cdot 10^{-3} \mathrm{~m}^{3} / \mathrm{s}$ in pipes with the diameter of 5 to $10 \mathrm{~mm}$.

The quality of the tasks to be accomplished depends on the flowrate measurement method applied in the flowmeter, its equipment and the technical and metrological characteristics of the equipment. Differential pressure flowmeters are widely applied for measurement of small and micro flowrates [1]. Differential pressure devices, hydraulic resistances in the form of CT and jet devices are applied as primary devices of these flowmeters [1]. The specified primary devices usually need to be calibrated individually.

Thus, the efficiency of up-to-date technological processes is defined to a significant extent by reliability and quality of automated monitoring and control systems operation. This circumstance causes high requirements to measurement equipment applied in the automation systems of the technological processes mentioned above and high requirements to the instruments for measurement of small and micro flowrates of gases.

In addition to the high accuracy of measurement there are strict requirements to the dynamic characteristics of such flowmeters. For instance, time constant of air flowmeters in the technological process of fiber optic cables production should not exceed a couple of seconds.

That is why the task of CT investigation is very important. They need to be investigated from the point of view of the possibility to apply them as hydraulic resistances for constructing the primary devices for measurement of small and micro flowrates of gases with low inertia and high accuracy of measurement without individual calibration.

\footnotetext{
"Corresponding author. Email address: ivan.d.stasiuk@1pnu.ua
} 


\section{Flowrate curves of capillary tubes}

Differential pressure flowmeters with hydraulic resistances as primary devices are considered in this work. The operation of such devices is based on the relation between the differential pressure across the resistance $\Delta P$ and the flowrate $Q$. Glass CTs with cylindrical channel are applied as the hydraulic resistance for the flowmeters of small and micro flowrates. These CTs provide laminar regime of gas flow. And the flowrate is defined on the basis of the absolute pressures $P_{1}$ and $P_{2}$ at the inlet and outlet of the capillary channel.

A number of functional expressions are applied as flowrate equations $Q=f\left(P_{1}, P_{2}\right)$ of such elements [1-5]. The difference between the calculation results based on different equations may rise up to $66 \%$ [6]. The accuracy of the result of flowrate calculation for any known equation depends on the dimensions of the capillary channel (diameter and length), type of relation $Q=f\left(P_{1}, P_{2}\right)$ and Reynolds number Re [5]. Let us study the effect of the specified factors on the flowrate with application of glass CTs as hydraulic resistances. They are produced of glass grade 360 according to GOST 1224-71 [7]. And they are applied in the instrument-making industry at production of glass liquid thermometers. The geometrical dimensions of CTs are regulated by the specifications for them. Microscopic number of the channel is the main dimensional characteristic of a CT. It is a one quarter of the arithmetic mean diameter along the big and small axis of this channel at the end expressed in micrometers. Glass CTs are wear-resistant, anticorrosive and can work with chemically aggressive fluids.

CTs with channel diameter $d$ from 0.06 to $2 \mathrm{~mm}$ (corresponding microscopic numbers 15 to 500 ) and length $L$ from 150 to $650 \mathrm{~mm}$ are applied at production of glass liquid thermometers. CTs with channel length from 10 to $300 \mathrm{~mm}$ and diameter from 0.09 to $0.3 \mathrm{~mm}$ are studied. Thus, for instance, CTs with $d=0.096 \mathrm{~mm}$ are studied for the lengths from 10 to $290 \mathrm{~mm}$, and with $d=0.156 \mathrm{~mm}$ and $d=0.260 \mathrm{~mm}$ for the lengths from 10 to $280 \mathrm{~mm}$ and from 10 to $210 \mathrm{~mm}$, respectively. The difference in length between the neighboring capillaries under research was $10 \mathrm{~mm}$.

In order to find out the possibility of measurement of small and micro flowrates of gases by means of glass CTs without their individual calibration, the accuracy of different flowrate equations needs to be studied, including the known equations [1-5]:

$$
\begin{gathered}
Q=A\left(P_{1}^{2}-P_{2}^{2}\right) /(2 R T), \\
Q=A P_{2} \rho_{2} \ln \left(P_{1} / P_{2}\right), \\
Q=A P_{2} \rho_{s} \frac{\ln \left(P_{1} / P_{2}\right)}{1-(\kappa-1) \exp ((2-\kappa) / \kappa) \ln \left(P_{1} / P_{2}\right)}, \\
Q=A \rho_{2} \Delta P,
\end{gathered}
$$

as well as the equation derived by us [8]

$$
Q=\frac{4 \pi \mu L}{m}\left[\sqrt{1+\frac{m d^{4}\left(P_{1}^{2}-P_{2}^{2}\right)}{512 \mu^{2} L^{2} R T}}-1\right] .
$$

where $Q$ is mass flowrate of gas; $\mu$ is gas dynamic viscosity coefficient; $R$ is gas constant; $T$ is gas temperature; $\rho_{2}$ is gas density downstream of the hydraulic resistance; $\rho_{s}$ is gas density at standard conditions (pressure $P_{s}=101325 \mathrm{~Pa}$, temperature $T_{s}=273.15 \mathrm{~K}$ ); $\kappa$ is gas isentropic exponent; $m$ is a coefficient for taking into account the pressure losses at entrance sections of a capillary; $\Delta P=P_{1}-P_{2}$ is differential pressure across the capillary; $A=\pi d^{4} /(128 \mu L)$.

To assess the accuracy of formulae (1)-(5), the relation $Q=f\left(P_{1}, P_{2}\right)$ was defined experimentally for various diameters and lengths of capillary channels of glass tubes. Based on the experimental data the $\delta Q$ errors of calculated values of flowrate through the capillary channels of glass tubes according to (1)-(5) were defined. The analysis of these errors provided the possibility to define the most adequate flowrate equation. 
The errors of calculated flowrate values were defined according to the formula

$$
\delta Q=100 \cdot\left(Q-Q_{e}\right) / Q_{e},
$$

where $Q$ and $Q_{e}$ are calculated and experimental values of flowrate respectively for the same point of CT flowrate curve (for the same differential pressure across the capillary).

The experimental tests were carried out on a facility where there were gas pressure reducers, pressure stabilizers, reference pressure gauges and thermometers, a barometer and a film flowmeter [9]. Air was used as a working fluid. The experiments were made for CT differential pressures from 10 to $160 \mathrm{kPa}$ and atmospheric pressure at the outlet of the tube. Based on the experimental studies it was defined that $\delta Q$ errors of flowrate calculation depend on the type of equation $Q=f\left(P_{1}, P_{2}\right)$ and for all the equations these errors depend on Reynolds number, diameter and length of the capillary channel.

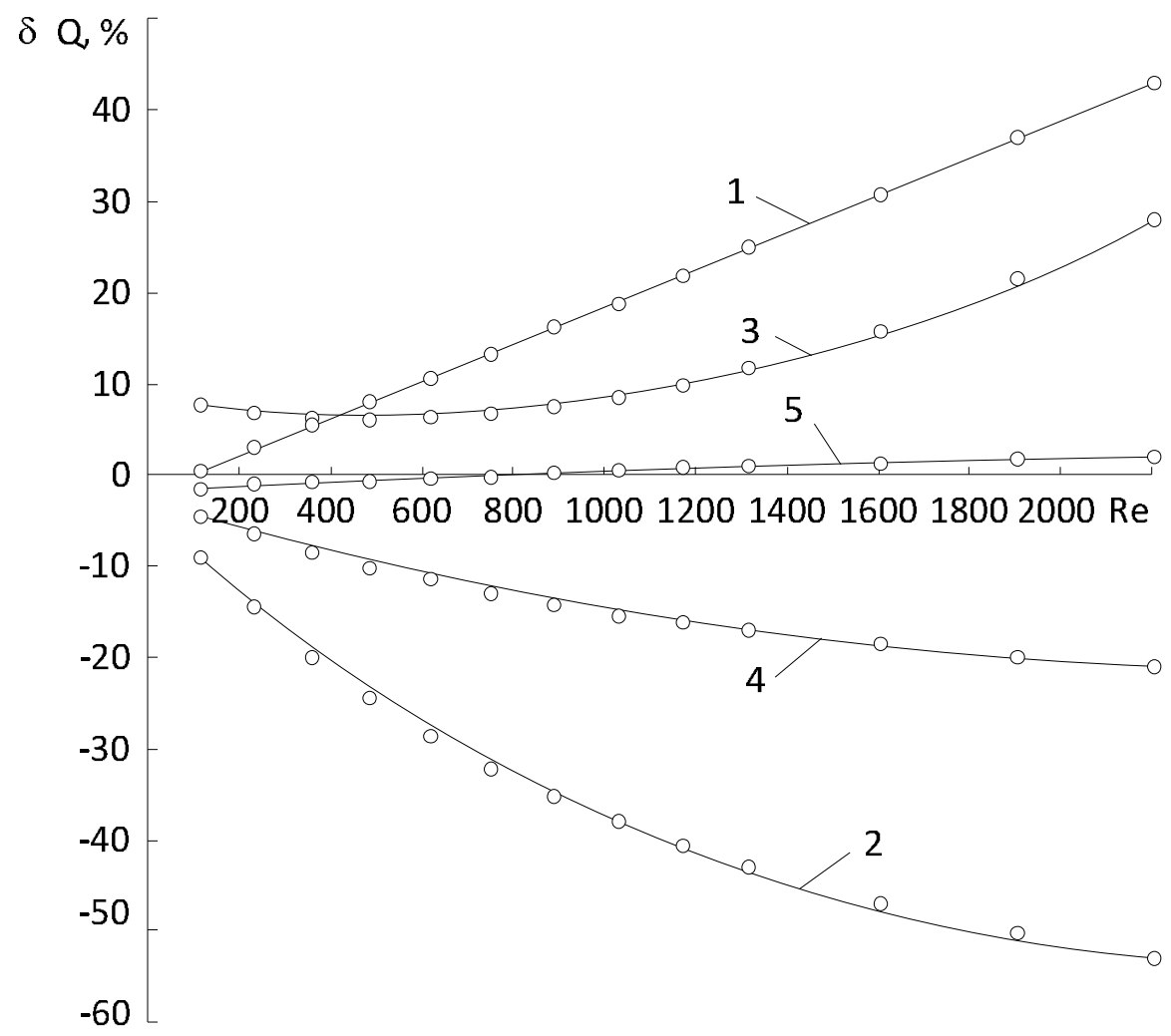

Fig. 1. Errors of flowrate calculation according to equations (1)-(5) versus Reynolds number for the capillary tube with $d=0.260 \mathrm{~mm}$ and $L=150.5 \mathrm{~mm}$

Based on the analysis of the effect of the factors mentioned above on $\delta Q$ errors of flowrate calculation according to equations (1)-(5), it was defined that equation (5) should be used as a flowrate equation for the CT under investigation. Using this equation it was defined that $\delta Q$ errors are less dependent on the diameter of the capillary channel, its length and, what is most important, vary insignificantly with the change of the differential pressure across the capillary (Re number). As an example the curves of errors of flowrate calculation according to equations (1)-(5) versus Reynolds number for the capillary tube with $d=0.260 \mathrm{~mm}$ and $L=150.5 \mathrm{~mm}$ are presented in Fig. 1. Working fluid was air. The pressure at the outlet of the tube $P_{2}$ was equal to atmospheric pressure. The curve numbers are correspondent to the equation numbers for which $\delta Q$ errors were defined. We can see from Fig. 1 that $\delta Q$ errors for equations (1)-(4) vary significantly with the change of Re number. And for equation (5) this variation is insignificant. The $\delta Q$ error of flowrate calculation according to (5) does not exceed $2 \%$ for this CT.

A similar pattern is observed for CTs with other diameters and lengths of capillary channels. The curves of $\delta Q$ errors of flowrate calculation according to (5) versus differential pressure $\Delta P$ for air flow through CTs with different dimensional sizes are presented in Fig. 2. The $\delta Q$ error of flowrate calculation for CT with $d=0.156 \mathrm{~mm}$ and 
$L=150 \mathrm{~mm}$ is within the limits from -0.5 to $0.6 \%$. For CT with $d=0.096 \mathrm{~mm}$ and $L=290 \mathrm{~mm}$ this error is from 0.3 to $1.9 \%$. And for CT with $d=0.096 \mathrm{~mm}$ and $L=150 \mathrm{~mm}$ this error is from -0.2 to $1.7 \%$.

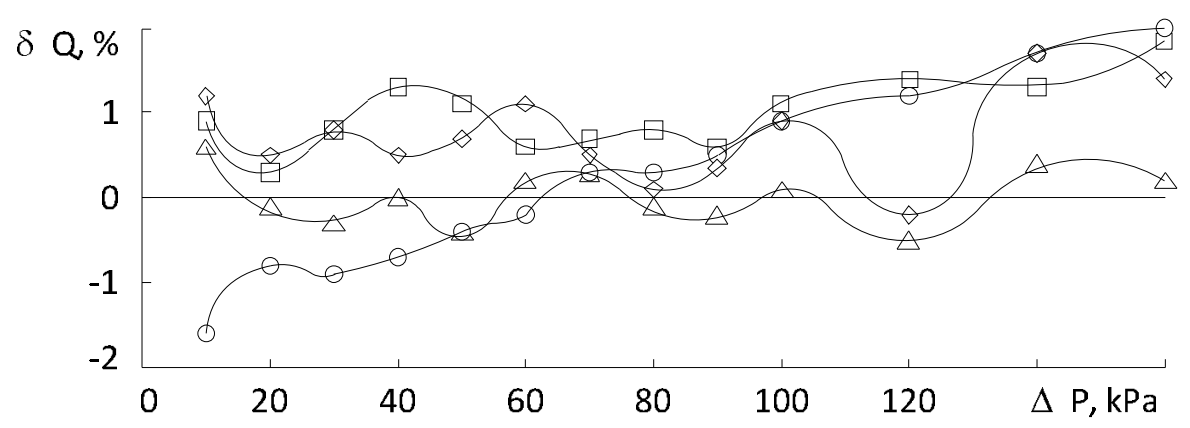

Fig. 2. Errors of flowrate calculation according to (5) versus differential pressure $\Delta P$ for air flow through CTs with the following dimensional sizes:

$\circ-d=0.26 \mathrm{~mm}$ and $L=150.5 \mathrm{~mm} ; \triangle-d=0.156 \mathrm{~mm}$ and $L=150 \mathrm{~mm}$;

$\square-d=0.096 \mathrm{~mm}$ and $L=290 \mathrm{~mm} ; \diamond-d=0.096 \mathrm{~mm}$ and $L=150 \mathrm{~mm}$

Thus, application of equation (5) as a flowrate equation for CT in the investigated range of dimensional sizes provides the possibility to apply the $\mathrm{CT}$ as primary devices for flowrate measurement without individual calibration. The limiting relative error of flowrate measurement in this case is in within the limits from 4 to $12 \%$ depending on the diameter of the capillary channel. The increase of the diameter leads to the decrees of the error which is explained by the fact that for CTs with different diameters of capillary channels and with equal absolute error the relative error of defining the diameter $d$ is different.

The $\delta Q$ error of flowrate calculation according to (5) for CTs under investigation takes the smallest value for coefficient $m$ equal to 2.8. To prove this, the errors of flowrate curves according to (5) for CT with $d=0.156 \mathrm{~mm}$ and $L=150 \mathrm{~mm}$ for the defined value $m=2.8$ and for $m=1.08$ according to $[1,2]$ are presented in Table 1 .

Table 1. Errors of flowrate curves according to (5) for a glass capillary tube with $d=0.156 \mathrm{~mm}$ and $L=150 \mathrm{~mm}$ for the value of coefficient of losses $m$ according to [1,2] and for the defined value of $m$

\begin{tabular}{|c|c|c|c|}
\hline \multirow{2}{*}{$\Delta P / 98.0665, \mathrm{kPa}$} & $Q_{e} \cdot 10^{9}, \mathrm{~kg} / \mathrm{s}$ & $m=1.08$ & \multicolumn{2}{|c|}{$\delta Q$, according to (5) for } \\
\cline { 3 - 4 } & 62.70 & 0.7 & 0.6 \\
\hline \hline 0.1 & 131.67 & 0.2 & -0.1 \\
\hline 0.2 & 206.08 & 0.2 & -0.3 \\
\hline 0.3 & 285.03 & 0.7 & 0 \\
\hline 0.4 & 371.05 & 0.5 & -0.4 \\
\hline 0.5 & 458.10 & 1.4 & 0.2 \\
\hline 0.6 & 552.21 & 1.6 & 0.3 \\
\hline 0.7 & 654.93 & 1.5 & -0.1 \\
\hline 0.8 & 760.28 & 1.7 & -0.2 \\
\hline 0.9 & 867.62 & 2.2 & 0.1 \\
\hline 1.0 & 1107.10 & 2.1 & -0.5 \\
\hline 1.2 & 1346.85 & 3.6 & 0.4 \\
\hline 1.4 & 1616.35 & 4.1 & 0.2 \\
\hline
\end{tabular}

Equation (5) provides high accuracy only in the case when CT diameter $d$ is defined also with high accuracy. If $d$ is defined with an error then it leads to the error of flowrate $Q$ calculation. In this case $\delta Q$ error does not depend on the differential pressure across the CT. The similar situation takes place when the capillary channel length $L$ is defined and when the pressure losses coefficient $m$ is defined. The $\delta Q$ error in these cases is a systematic error caused by inaccurate definition of capillary parameters. 
Based on the analysis of the accuracy of defining the $d, L, m$ parameters of a capillary it was found that length $L$ can be defined with a relative error from 0.01 to $0.1 \%$. Diameter $d$ can be defined with the error from 2.0 to $6.0 \%$. The accuracy of defining the coefficient $m$ today is unknown.

Taking into account the information mentioned above, to raise the accuracy of flowrate measurement, the parameters $d$ and $m$ should be defined experimentally for each specific CT. Here it is reasonable to transform the equation (5) into the following form

$$
Q=B_{1} \mu \cdot\left\{\sqrt{1+B_{2}\left(P_{1}^{2}-P_{2}^{2}\right) /\left(T \mu^{2}\right)}-1\right\}
$$

and to define the coefficients $B_{1}=4 \pi L / m$ and $B_{2}=m d^{4} /\left(512 L^{2} R\right)$ experimentally based on two values of gas flowrate $Q_{e}$ and $Q_{e 2}$ in the CT at two different differential pressures $\Delta P_{1}$ and $\Delta P_{2}$ across the tube. This way the deviation of geometrical dimensions of CTs from the nominal ones will be taken into account.

A flowrate curve of a CT with $d=0.100 \mathrm{~mm}$ and $L=170.5 \mathrm{~mm}$ for air flow calculated using (6) is presented in Fig. 3. In this case, the experimental values of coefficients $B_{1}$ and $B_{2}$ were used in the equation (6). The values of these coefficients are $0.774 \mathrm{~m}$ and $5.65 \cdot 10^{-20} \mathrm{~K} \cdot \mathrm{s}^{2}$ respectively. The experimental values of air flowrate for various differential pressures across this CT and for the atmospheric pressure at the outlet of CT are also presented in Fig.3. It was defined that maximum deviation of the calculated values of flowrate (using the equation (6) and the experimental values of coefficients $B_{1}$ and $B_{2}$ ) from the experimental values of air flowrate in the specified range of measurement does not exceed $0.8 \%$ for the same tube.

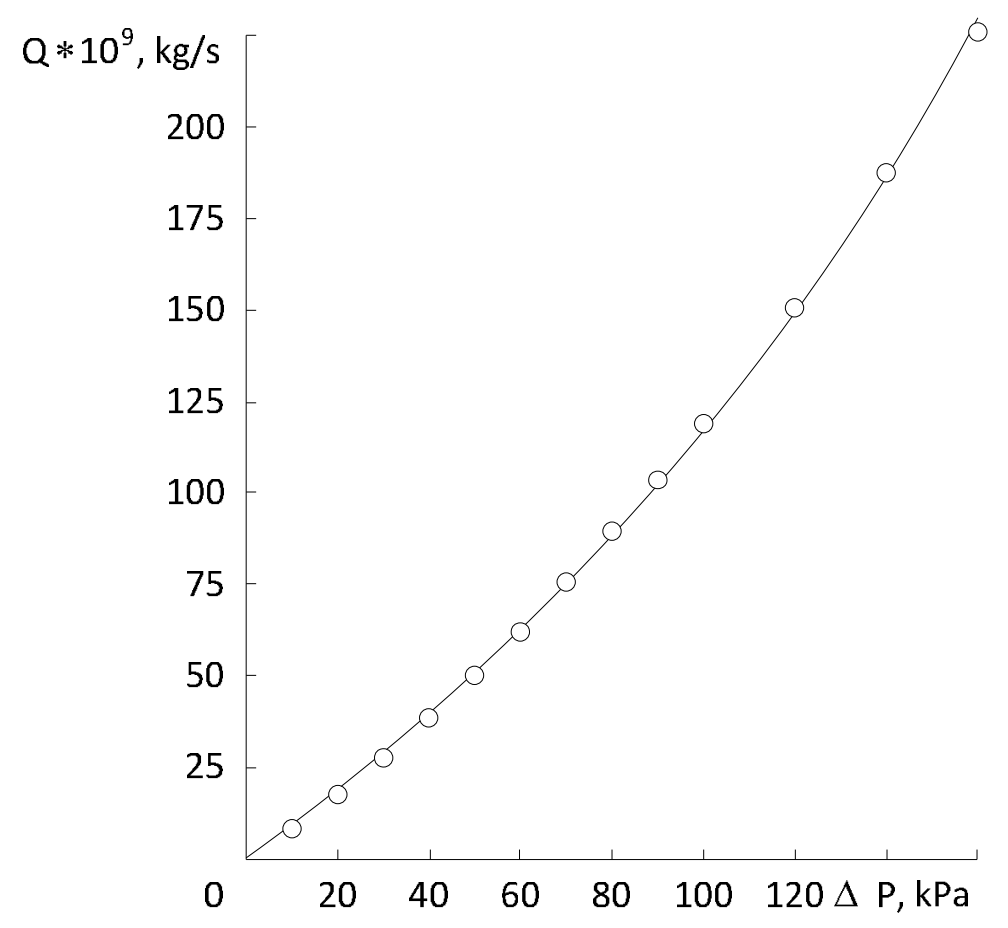

Fig. 3. Flowrate curves defined experimentally and calculated on the basis of equation (6) for a capillary tube with $d=0.100 \mathrm{~mm}$ and $L=170.5 \mathrm{~mm}$ for air flow

Based on the experimental studies, we can say that there is a great potential for application of CTs (hydraulic resistances) as primary devices for measurement of small and micro flowrates of gases.

\section{Gas dynamical capillary bridge transducers for measurement of small and micro flowrates of gases and their dynamic properties}

Gas dynamical capillary flowmeters constructed of glass capillaries are applied for measurement of small and micro flowrates of gases [10] in automated measurement and control systems during fiber optics production. The structural diagram of such a flowmeter is presented in Fig. 4. It consists of a GDCFT 1, secondary transducer 2 
(differential pressure gauge (DPG) with a unified electrical analog output signal) and secondary device 3.The DPG chambers are connected to the inter-capillary PMCs of GDCFT. GDCFT is constructed of laminar capillaries (glass CTs) according to the diagram of a gas dynamical capillary measuring bridge shown in Fig. 5.

The dynamical properties of such gas flowmeters are defined by the dynamical properties of each individual element of the flowmeter [11]

$$
W(p)=W_{1}(p) \cdot W_{2}(p) \cdot W_{3}(p),
$$

where $W(p)$ is the flowmeter transfer function; $W_{1}(p), W_{2}(p)$ and $W_{3}(p)$ are transfer functions of GDCFT, DPG and secondary device respectively.

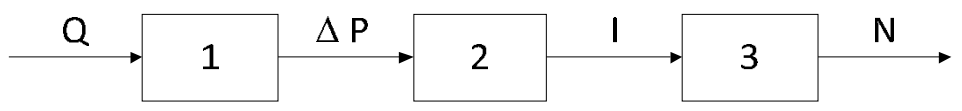

Fig. 4. Structural diagram of gas dynamical capillary flowmeter of small and micro flowrates of gas: 1 is a gas dynamical capillary flowrate transducer; 2 is a differential pressure gauge with a unified electrical analog output signal; 3 is a secondary device

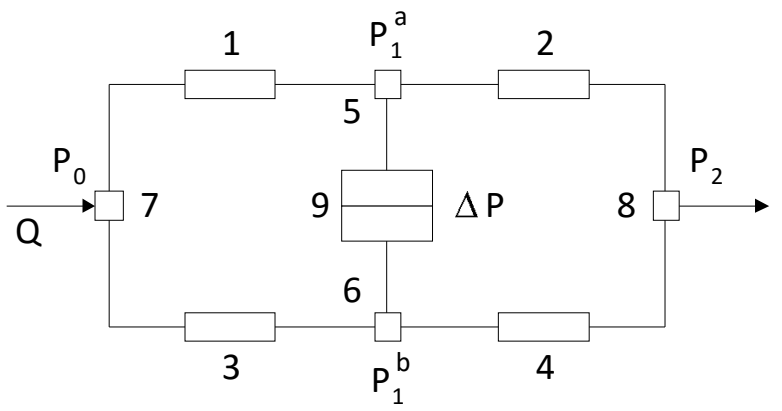

Fig. 5. Bridge measuring diagram of a gas dynamical capillary flowmeter:

$1,2,3,4$ - capillaries; 5 and 6 are inter-capillary pneumatic chambers;

7 and 8 are inlet and outlet pneumatic chambers; 9 are DPG chambers

Volumes of PMCs like dimensional specifications of CTs make significant influence on the dynamical properties of GDCFT. DPG chambers volumes make influence mainly on the dynamics of the secondary measuring transducer.

The peculiarity of the gas flowmeter construction is that each chamber of DPG together with the corresponding PMCs of GDCFT makes one common PMCs of a definite volume. During studying the dynamical properties of the flowmeter these two common PMCs can be taken into account either in GDCFT or in DPG, or separately in GDCFT and in DPG according to the component volumes of the whole common volume. Due to the fact that the dynamical properties of DPG are studied not enough and that the main difficulty during the study of the dynamical properties of DPG is accounting of DPG chambers volumes, it seems to be reasonable to take in to account the DPG chambers volumes in GDCFT.

Thus, the common PMCs volumes were taken into account in GDCFT during studying of dynamical properties of the flowmeter. The transfer function of DPG $W_{2}(p)$ in this case can be presented as a proportional element with the gain coefficient

$$
K_{2}=\Delta I /(\Delta(\Delta P))
$$

where $\Delta I$ and $\Delta(\Delta P)$ are variations of output and input signals of DPG respectively.

If we assume that the secondary device is also a proportional element, then let's consider the dynamical characteristics of GDCFT with taking into account the information mentioned above.

GDCFT (see Fig. 5) consists of two parallel branches. CTs 1 and 2 make the first branch and CTs 3 and 4 make the second branch. There are PMCs 5 and 6 between these CTs. The PMCs together with DPG volumes and the connecting pneumatic lines make the flow-through pneumatic chambers of constant volumes with constant laminar resistances at inlet and outlet. 
Thus, the measuring diagram of the gas flowmeter (consisting of GDCFT and DPG) is made of two parallel flow-through PMCs. The CTs upstream pressures at the inlet of the chambers are equal and stabilized. And the CTs downstream pressures at the outlet of the chambers are also equal and stabilized.

Taking into account the parallel junction of the flow-through PMCs and measurement of differential pressure across them, the transfer function of GDCFT can be presented as follows

$$
W_{1}(p)=W_{a}(p)-W_{b}(p)
$$

where $W_{a}(p)$ and $W_{b}(p)$ are transfer functions of upper and lower flow-through PMCs respectively with their CTs.

Let's consider the dynamic properties of a particular common flow-through PMC of GDCFT presented in Fig.6. In case of steady flow the flowrate through the flow-through chamber and capillaries 1 and 2 (which are parts of the chambers) is constant. Pressures $P_{0}, P_{1}$ and $P_{2}$ are also constant. Pressure $P_{1}$ may vary depending on the pressures $P_{0}$ and $P_{2}$. So, there are two inputs $\left(P_{0}\right.$ and $\left.P_{2}\right)$ for the output pressure $P_{1}$. If pressure $P_{2}$ is stabilized (which is made in the GDCFT under consideration by means of the absolute pressure stabilizer) then pressure $P_{1}$ will vary only due to variation of pressure $P_{0}$.

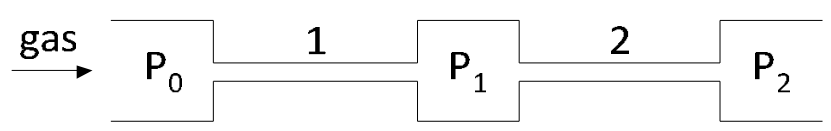

Fig. 6. Pneumatic chamber of constant volume with laminar capillaries at inlet and outlet

Transfer function of such a chamber for the channel $P_{0} \rightarrow P_{1}$ corresponds to the first order lag element [11]

$$
W(p)=K /(T p+1)
$$

where $K=K_{1} /\left(K_{1}+K_{2}\right)$ is the gain coefficient for the input $P_{0} ; T=V /\left[R \Theta\left(K_{1}+K_{2}\right)\right]$ is time constant of the chamber.

There are two flow-through PMCs in GDCFT according to Fig. 5. These PMCs make influence on the dynamic characteristics of GDCFT according to equation (8). These chambers are the same as in Fig. 6.

Transfer function of upper chamber 5 and lower chamber 6 (see Fig. 5) is similar to (9) and is defined as follows

$$
W_{a(b)}(p)=K_{a(b)} /\left(T_{a(b)} p+1\right),
$$

where

$$
K_{a(b)}=K_{1(3)} /\left(K_{1(3)}+K_{2(4)}\right) ; T_{a(b)}=V_{a(b)} /\left[R \Theta\left(K_{1(3)}+K_{2(4)}\right)\right\rfloor
$$

where $K_{i}=\pi d_{i}^{4} \rho_{i} /\left(128 \mu L_{i}\right), i=1,2,3,4$ is conductivity of $i$-th CT; $V_{a}$ and $V_{b}$ are volumes of upper and lower PMCs respectively; $R$ is the universal gas constant; $\Theta$ is absolute temperature of gas in the chamber.

Thus, transfer function of GDCFT according to (8) and (10) is defined as follows

$$
W_{1}(p)=\frac{K_{a}}{T_{a} p+1}-\frac{K_{b}}{T_{b} p+1}=\frac{K_{a}-K_{b}+\left(K_{a} T_{b}-K_{b} T_{a}\right) p}{T_{a} T_{b} p^{2}+\left(T_{a}+T_{b}\right) p+1}
$$

It follows from (12) that dynamical characteristics of GDCFT depending on the ratio of PMC volumes, CT sizes and gas thermo-physical parameters can be described both by a second order lag element and by a differential element. To eliminate differentiation the following condition should be observed [11]

$$
K_{a} T_{b}-K_{b} T_{a}=0
$$

which can be obtained by appropriate choice of PMC volumes for the given CTs. In addition, it can be seen from (12) that inertia of GDCFT is defined by $T_{a}$ and $T_{b}$. The values of $T_{a}$ and $T_{b}$ can be changed by changing the volumes $V_{a}$ 
and $V_{b}$ of GDCFT PMCs. It follows from the material presented above that to make GDCFT dynamical characteristics meet the requirements of up-to-date technologies the volumes of chambers $V_{a}$ and $V_{b}$ should be minimal and the condition (13) should be observed.

It should be mentioned that there is a special case of GDCFT when time constants $T_{a}$ and $T_{b}$ are equal. In this case the transfer function of a first order lag element (9) with $K=K_{a}-K_{b}$ and $T=T_{a}=T_{b}$ is obtained from (12). It is obvious that this case is the best one during construction of GDCFT. Here GDCFTs with dynamical characteristics meeting the requirements of up-to-date productions can usually be constructed by decreasing $T_{a}$ and $T_{b}$ and making them equal.

According to the accepted methodology where the dynamical properties of DPG chambers are included into the GDCFT transfer function, the transfer function of DPG is presented by a proportional element $W_{2}(p)=K_{D}=\Delta I /(\Delta(\Delta P))$. The dynamics of the secondary devices is known and can be described by the transfer function of a proportional element or a first order lag element.

Thus, the inertia of a gas flowmeter depends basically on the dynamical properties of GDCFT and secondary device.

\section{Conditions to secure given dynamical characteristics of gas dynamical meters of small and micro flowrates of gases}

The dynamical characteristics of a gas dynamical flowmeter (see part 3) are basically defined by GDCFT PMCs volumes. The volume of a GDCFT PMC is the sum of volumes of GDCFT inter-capillary chamber, DPG chamber and the connecting pneumatic line.

Let's consider the technique for defining the ratio of GDCFT PMC volumes to secure the given dynamical characteristics of flowmeters for small and micro flowrates of gases.

Let's define the ratio of PMC volumes which is needed to observe the condition (13) providing elimination of differentiation effect on GDCFT output signal. This condition can be presented as follows

$$
T_{a} / T_{b}=K_{a} / K_{b}
$$

The formulae for defining $K_{a}, K_{b}, T_{a}$ and $T_{b}$ as well as $K_{1}$ and $K_{3}$ from (11) are substituted to (14) and we obtain

$$
V_{a} / V_{b}=d_{1}^{4} \rho_{1} L_{3} /\left(d_{3}^{4} \rho_{3} L_{1}\right) .
$$

In case of $d_{1}=d_{2}=d_{3}=d_{4}=d$ (the diameters of capillary channels of all CTs are equal), $L_{1}=L_{4}=L_{S}$ (the same short CTs) and $L_{2}=L_{3}=L_{L}$ (the same long CTs) equation (15) will be as follows

$$
V_{a} / V_{b}=\rho_{1} L_{L} /\left(\rho_{3} L_{S}\right) .
$$

Gas average densities $\rho_{1}$ and $\rho_{3}$ along the 1 st and the 2nd CT channels are defined by the following equation

$$
\rho_{1(3)}=P_{1(3)_{\text {aver }}} /(\Theta R)
$$

where average pressures $P_{1(3) \text { aver }}$ along channels of CT at the chamber input (see Fig. 6) and CT at the chamber output respectively are defined on the basis of the following approximated formulae

$$
P_{1(3)_{\text {aver }}}=\left(P_{0}+P_{1}^{a(b)}\right) / 2 \text {. }
$$

Since differential pressure $\Delta P=P_{1}{ }^{a}-P_{1}{ }^{b}$ in the measuring diagonal of GDCFT is insignificant in comparison to the input pressure $P_{0}$ (for instance, for oxygen flowmeter with flowrate range of $Q_{\max }=5 \cdot 10^{-6} \mathrm{~m}^{3} / \mathrm{s}(181 / \mathrm{h})$ the absolute pressure of gas at the input of the transducer at maximum flowrate is equal to $P_{0}=143.415 \mathrm{kPa}$ and maximum differential pressure in the measuring diagonal $\Delta P=1 \mathrm{kPa}$ ), the difference between the sums of pressures $P_{0}+P_{1}{ }^{a}$ and $P_{0}+P_{1}^{b}$ is also insignificant. These sums of pressures characterize the average pressures $P_{\text {laver }}$ and $P_{2 a v e r}$ in formulae (16) for defining the gas densities $\rho_{1}$ and $\rho_{3}$. It means that in this case the gas densities $\rho_{1}$ and $\rho_{3}$ are approximately equal. Since $\rho_{1} \approx \rho_{3}$, formula (16) can be presented as follows

$$
V_{a} / V_{b} \approx L_{L} / L_{S}
$$


Thus, to eliminate the differentiation effect to the output signal of GDCFT at any sizes of CTs and any thermophysical gas parameters, the ratio of PMC volumes should meet the condition (15) and in case when $d_{1}=d_{2}=d_{3}=d_{4}=d$, $L_{1}=L_{4}=L_{L}$ and $L_{2}=L_{3}=L_{L}$ this ratio should meet the condition (19).

Now let's analyze what ratio of GDCFT PMC volumes should be to make its dynamics correspond to the first order lag element which is possible when time constants are equal $T_{a}=T_{b}$. Based on (11) for the volumes of GDCFT PMCs this condition can be defined as follows

$$
\frac{V_{a}}{R \Theta\left(K_{1}+K_{2}\right)}=\frac{V_{b}}{R \Theta\left(K_{3}+K_{4}\right)} .
$$

The ratio of PMC volumes based on condition (20) can be written as follows

$$
V_{a} / V_{b}=\left(K_{1}+K_{2}\right) /\left(K_{3}+K_{4}\right) \text {. }
$$

After substituting $K_{1}, K_{2}, K_{3}$ and $K_{4}$ from (11) to (21) we obtain

$$
\frac{V_{a}}{V_{b}}=\frac{\left(d_{1}^{4} \rho_{1} L_{2}+d_{2}^{4} \rho_{2} L_{1}\right) L_{3} L_{4}}{\left(d_{3}^{4} \rho_{3} L_{4}+d_{4}^{4} \rho_{4} L_{3}\right) L_{1} L_{2}}
$$

In case of $d_{1}=d_{2}=d_{3}=d_{4}=d, L_{1}=L_{4}=L_{S}$ and $L_{2}=L_{3}=L_{L}$ condition (22) is written as

$$
V_{a} / V_{b}=\left(\rho_{1} L_{L}+\rho_{2} L_{S}\right) /\left(\rho_{3} L_{S}+\rho_{4} L_{L}\right)
$$

The average gas densities along the capillary channels $\rho_{1}, \rho_{2}, \rho_{3}$ and $\rho_{4}$ can be expressed by the average pressures in these channels $P_{1 \text { aver }}, P_{2 a v e r}, P_{3 a v e r}$ and $P_{4 a v e r}$. In this case condition (23) can be presented as follows

$$
\frac{V_{a}}{V_{b}}=\frac{\rho_{1}\left(P_{0}+P_{1}^{a}\right) L_{L}+\rho_{2}\left(P_{1}^{a}+P_{2}\right) L_{S}}{\rho_{3}\left(P_{0}+P_{1}^{b}\right) L_{S}+\rho_{4}\left(P_{1}^{b}+P_{2}\right) L_{L}}
$$

Thus, to make the dynamics of GDCFT correspond to the first order lag element at any sizes of CTs and any thermo-physical gas parameters, the ratio of PMC volumes should meet the condition (22) and in case when $d_{1}=d_{2}=d_{3}=d_{4}=d, L_{1}=L_{4}=L_{L}$ and $L_{2}=L_{3}=L_{L}$ this ratio should meet the condition (24).

Based on the material presented above it follows that to make GDCFT dynamical characteristics meet the requirements of up-to-date technologies the volumes of chambers $V_{a}$ and $V_{b}$ should be minimal and the conditions (15) or (19) should be observed to eliminate differentiation, or conditions (22) or (24) to make the dynamics of GDCFT correspond to the first order lag element.

For example, to make GDCFT in an oxygen flowmeter with the range of measurement from 0 to $5 \cdot 10^{-6} \mathrm{~m}^{3} / \mathrm{s}$ (from 0 to $18 \mathrm{l} / \mathrm{h}$ ) correspond to the first order lag element with the time constant $T \leq 1 \mathrm{~s}$ the volumes of its PMCs should be $V_{a}=149.8 \cdot 10^{-6} \mathrm{~m}^{3}$ i $V_{b}=148.2 \cdot 10^{-6} \mathrm{~m}^{3}$. The construction sizes of CTs in this GDCFT are as follows: $d=0.3 \cdot 10^{-3} \mathrm{~m} ; L_{L}=0.02006 \mathrm{~m} ; L_{S}=0.015 \mathrm{~m}$. Maximum differential pressure in the measurement diagonal of GDCFT is $\Delta P=1 \mathrm{kPa}$. Input absolute pressure at maximum flowrate is $P_{0}=143.415 \mathrm{kPa}$ and output absolute pressure is $P_{2}=130 \mathrm{kPa}$. The oxygen dynamic viscosity coefficient at temperature of $\Theta=313.15 \mathrm{~K}$ is $\mu=2124.6 \cdot 10^{-8} \mathrm{~Pa} \cdot \mathrm{s}$.

The obtained values of PMC volumes $V_{a}$ and $V_{b}$ should be taken into account during construction of GDCFT module and during selection of DPG for flowmeters of small and micro flowrates of gases.

The results of the conducted investigations may find application during development and construction of gas dynamical capillary flowmeters and setting devices of small and micro flowrates of gases.

\section{Conclusion}

Based on the studies we carried out, it was shown that equation (5) can be applied as flowrate equation for glass CTs with the length of internal channels from 10 to $300 \mathrm{~mm}$ and with the diameter from 0.09 to $0.30 \mathrm{~mm}$. The glass capillary tubes can be applied as primary transducers of flowrate without individual calibration. The limiting errors of the flowrate measurement results in this case are from 4 to $12 \%$. 
It was defined that in the range of Reynolds numbers from 100 to 2200, the maximum deviation of the calculated values of air flowrate through CTs (in case of application of equation (6) and the experimental values of coefficients $B_{1}$ and $B_{2}$ ) from the experimental values of flowrate for the same CT does not exceed $0.8 \%$.

The dynamical properties of GDCFT may correspond to a second order lag element or a differential element and it depends on the ratio of PMC volumes, geometrical dimensions of CTs and thermo-physical parameters of gas. To eliminate the differentiation the condition (9) should be observed. And to make GDCFT dynamical properties meet the requirements of up-to-date technologies the volumes of PMCs should be minimal.

To make the dynamical properties of GDCFT correspond to a first order lag element for any dimensional sizes of CTs and for any values of gas parameters the ratio of PMC volumes should meet the condition (22), and in case when $d_{1}=d_{2}=d_{3}=d_{4}=d, L_{1}=L_{4}=L_{S}$ and $L_{2}=L_{3}=L_{L}$ condition (24) should be observed. The obtained results can be applied at development of gas dynamical capillary flowmeters for small and micro flowrates of gases.

\title{
References
}

[1] Kremlevskiy P. P. Flow and Volume Meters. - Leninhrad : Mashynostroenie, 1975. - 776 p. (in Russian)

[2] Dembovskiy V. V. Peculiarities of gas flow in capillary channels // Measurement instrumentation. - 1968. - No. 6. - P. 44-45. (in Russian)

[3] Zaporozhets V. P., Vlasov Yu. D., Lavrov K. G. Design of capillaries applied for dosing small volumes of gases // Measurement instrumentation. - 1974. - No. 5. - p. 27. (in Russian)

[4] Zaporozhets V. P. Metrological peculiarities of capillary method of gas viscosity measurement // Metrology. - 1975. - No. 10. - P. 37-41. (in Russian)

[5] Zalmanzon L. A. Flow-through elements of pneumatic devices for monitoring and control. - M.: Publ. House of AS of USSR, 1961. - 248 p. (in Russian)

[6] Stasiuk I. D. Development of gas dynamical capillary transducers of small and micro flowrates of gases: Abstract of Dissertation of Cand. of Techn. Sci.: 05.11.01 / A. Snechkus Kaunas Polytechnic Institute. - Kaunas, 1988. - 17 p. (in Russian)

[7] GOST 1224-71. Thermometric glass. Grades. - Moscow : Publ. House of Standards. (in Russian)

[8] Pistun E. P., Stasiuk I. D., Tepliukh Z. M. Investigation of flowrate curves of capillary elements of measurement instruments // Control and Measurement Instrumentation. - 1985. - Issue 38. - P. 44-46. (in Russian)

[9] Pistun E. P., Stasiuk I. D., Tepliukh Z. M. Definition of flowrate curves of capillary elements // Automation and control and measurement instrumentation in oil-refinery and oil-chemical industry. - 1982. - No. 4. P. 28-30. (in Russian)

[10] Copyright Certificate No. 1278584 (USSR). Device for measurement of small flowrates // E. P. Pistun, I. D. Stasiuk, Bulletin No. 47 , 1986. (in Russian)

[11] Pistun E. P., Stasiuk I. D. Investigation of dynamical properties of gas dynamical capillary flowmeters of small and micro flowrates of gases // Methods and Instruments for Quality Control. - 2000. - No. 5. - P. 35-38. (in Ukrainian)

\section{Газодинамічні капілярні витратоміри малих і мікровитрат газів}

\author{
Іван Стасюк
}

\author{
Національний університет “Львівська політехніка”, вул. С. Бандери, 12, м. Львів, 29013, Україна
}

\section{Анотація}

Обгрунтовано можливість застосування скляних капілярних трубок (КТ) як чутливих елементів малих і мікровитрат газів. На підставі експериментальних досліджень витратних характеристик КТ проаналізовано точність різних аналітичних виразів як рівнянь витрати цих КТ. Показано можливість їхнього застосування як первинних вимірювальних перетворювачів малих і мікровитрат газів без індивідуального градуювання. Наведено результати досліджень динамічних властивостей газодинамічних дросельних витратомірів малих $\mathrm{i}$ мікровитрат газів, побудованих на базі скляних КТ, включених у плечі мостової вимірювальної схеми. Проаналізовано вплив різних чинників на динамічні властивості газодинамічних дросельних вимірювальних перетворювачів витрати (ГДВПВ). Наведено рекомендації щодо виконання міждросельних вимірювальних пневматичних камер (ВПК) ГДВПВ для забезпечення необхідних динамічних властивостей таких витратомірів. Описано методику визначення необхідного (з погляду забезпечення заданих динамічних характеристик витратомірів) співвідношення об’ємів ВПК ГДВПВ під час їхнього конструювання.

Ключові слова: капілярна трубка; малі та мікровитрати газу; точність; стала часу. 